\title{
UTILIZAÇÃO DE BANCADAS DE ENSAIO PARA ESTUDO DO COMPORTAMENTO DINÂMICO DE MÁQUINAS ROTATIVAS - VIBRAÇÕES MECÂNICAS -
}

\author{
S. S. de Jesus e P. F. Cavalcante \\ Departamento de Engenharia Mecânica da Universidade Federal da Bahia \\ solival87@hotmail.com - pfc@ufba.br
}

Artigo submetido em maio/2011 e aceito em junho/2011

\section{RESUMO}

As máquinas rotativas são equipamentos utilizados nos diversos ambientes do cotidiano, tornando-se elementos indispensáveis nas atividades humanas. Devido ao alto nível de exigência em tais especialidades, conhecer o comportamento dinâmico dessas máquinas é fundamental. Como estudo de caso neste trabalho foi feito a análise experimental para um conjunto suportado por 2 mancais de deslizamento, localizado na Refinaria Landulpho Alves (RLAM) - PETROBRAS, e em seguida, foi analisado a resposta para o fenômeno de desbalanceamento, desalinhamento e roçamento. Como resultado tem-se a obtenção de conhecimento relativo aos principais fenômenos que afetam os equipamentos rotativos, através da aquisição de dados e análise da resposta do sistema simulando condições específicas de operação de equipamentos industriais, podendo-se assim, investigar, entre outros, fenômenos tais como desalinhamentos e desbalanceamentos em máquinas.

PALAVRAS-CHAVE: Máquinas rotativas, análise de vibrações, diagnóstico de defeitos.

\section{USE OF TABLES OF TEST FOR STUDY OF THE DYNAMIC BEHAVIOR OF ROTATING MACHINES - MECHANICAL VIBRATIONS -}

\section{ABSTRACT}

Rotating machines are devices used in different environments of daily life, becoming indispensable elements in human activities. Due to the high level of demand in such specialties, a deep knowledge of the dynamic behavior of these machines is essential. This work talks is showed the assembly procedures, data acquisition and analysis of a rotorbearing assembly on a test bench in existing Landulpho Alves (RLAM) - PETROBRAS. The result has been to obtain knowledge on the main phenomena that affect the rotating equipment through the data acquisition and analysis of system response by simulating some conditions of operation of industrial equipment, can thus, to investigate, among other phenomena such as misalignment and imbalance.

KEY-WORDS: Rotating Machinery, Bench Testing, Vibration Analysis, Dynamic Behavior, Diagnosis of Defects. 


\section{UTILIZAÇÃO DE BANCADAS DE ENSAIO PARA ESTUDO DO COMPORTAMENTO DINÂMICO DE MÁQUINAS ROTATIVAS - VIBRAÇÕES MECÂNICAS -}

\section{INTRODUÇÃO}

Os equipamentos dinâmicos têm fundamental importância no cenário industrial moderno. Nos mais diversos seguimentos industriais, a utilização de equipamentos rotativos como bombas, compressores, turbinas, dentre outros, revela a necessidade de conhecer de maneira aprofundada os comportamentos dessas máquinas. Nesse contexto, ao longo das últimas décadas, muito tem se evoluído no sentido de compreender os fenômenos responsáveis pelo desempenho dinâmico dos sistemas rotativos. A análise dos modos de vibração, tem se destacado como uma eficiente ferramenta no monitoramento dessas condições.

A complexidade no exame do comportamento das máquinas rotativas decorre da necessidade de se estudar os efeitos das interações e as respostas aos estímulos internos dos conjuntos de componentes. Nessa tentativa de avaliar conceitos, validar modelos teóricos e possibilitar o desenvolvimento de projetos, o uso de bancadas experimentais simulando a operação de sistemas reais é um método amplamente conhecido e extensivamente usado nos centros de pesquisas e em universidades. Kirovski (1997), afirma que a engenharia sempre necessitou testar conceitos e aplicações em escala reduzida nas mais variadas áreas, e que com o desenvolvimento e evolução da eletrônica e instrumentação o uso de sistemas experimentais para simulação e teste tornou-se muito mais simples e usual, tendo em vista que sistemas computacionais de aquisição de dados e microprocessadores passaram ser utilizados de forma mais disseminada.

Com esse panorama, a utilização de bancadas de testes, como apoio às áreas de projetos, pesquisa e ensino tem crescido significativamente. Bancadas de ensaios são utilizadas como ferramentas auxiliares em aplicações de engenharia que englobam eletrônica embarcada e análise de sinais, já que se podem programar sistemas completos para simulação de características técnicas que são encontradas em sistemas reais (Bryan et al., 1989).

O desenvolvimento desse trabalho tem como motivação a obtenção de conhecimento sobre estruturas experimentais utilizadas para a validação das teorias relativas à Análise de Vibração e que dão subsídio ao desenvolvimento das técnicas utilizadas pela Manutenção Preditiva. Nesse sentido, as bancadas de ensaio ganham destaque à medida que podem ajudar na compreensão das respostas em vibração, promovidas pela existência de peculiaridades nos sistemas mecânicos simulados. Também é desejado ao longo deste trabalho, o conhecimento a respeito dos sistemas de aquisição de dados (sensores, analisadores e pontos de aquisição) e como se processa a interpretação destes. Além disso, o projeto de um novo conjunto rotor-mancal, para implementação na bancada existente na Refinaria Landulpho Alves (RLAM) - PETROBRAS é motivado, para permitir assim, a utilização da mesma de uma maneira mais abrangente em treinamentos, simulando melhor as condições existentes nas máquinas rotativas em campo.

A metodologia aplicada neste trabalho baseia-se inicialmente, em fazer um estudo das Vibrações Mecânicas e das principais alterações nos comportamentos vibratórios das máquinas rotativas quando sujeitas a anormalidades. Em seguida, é feito um estudo das principais estruturas 
utilizadas nas simulações operacionais, e com o caráter experimental, é feita, efetivamente, as simulações em uma bancada.

\section{REVISÃO BIBLIOGRÁFICA}

A resposta dinâmica de estruturas mecânicas tem sido alvo de investigação de um grande número de pesquisadores. Dentre os objetivos de tal esforço, pode-se destacar a caracterização das freqüências, modos próprios de vibrar e o estudo da resposta a diferentes excitações. A compreensão dessas características permite ao projetista ou mantenedor alterar conscientemente, determinados parâmetros de um dado projeto, tais como dimensões e materiais, de modo a obter ou modificar condições específicas do comportamento de máquinas, motivadas por redução do custo de fabricação, aumento da confiabilidade, disponibilidade e desempenho (Oliveira, 1999).

Sempre houve necessidade de a engenharia testar conceitos em escala reduzida nas mais diversas áreas, para a produção e aperfeiçoamento do conhecimento. Daí, o uso de bancadas experimentais simulando a operação de sistemas reais ter se tornado um método amplamente conhecido e extensivamente usado para o desenvolvimento desses conceitos fundamentais, necessários na elaboração de projetos em geral. Nessa conjuntura a Análise de Vibrações ganha destaque como uma ferramenta fundamental na investigação e na produção de conhecimento sobre o comportamento das construções mecânicas (Amorim, 2006). Assim, a primeira parte do trabalho aborda a Teoria das Vibrações, enfatizando definições e conceitos básicos, enquanto a parte final trata da identificação e diagnóstico de falhas em máquinas rotativas, fazendo uso de conhecimentos sobre os modos de vibrar das estruturas mecânicas.

\subsection{QUANTIFICAÇÃO DA VIBRAÇÃO EM EQUIPAMENTOS ROTATIVOS}

Segundo Rao (2009), qualquer movimento que se repete após um intervalo de tempo pode ser denominado vibração. Silva (2009) concorda com Rao ao afirmar que um movimento periódico, tal como uma oscilação de uma partícula, de um sistema de partículas ou de um corpo rígido, em torno de uma posição de equilíbrio é definida como vibração.

É muito importante destacar como se dá a quantificação da condição de vibração em equipamentos rotativos. Movimentos oscilatórios de vibração podem ser expressos em função das grandezas deslocamento, velocidade e aceleração, sendo que cada uma têm diferentes utilidades na análise dinâmica de equipamentos.

Na observação de um fenômeno vibratório, o conteúdo de freqüências depende do agente causador e do ambiente pelo qual se propaga. A observação dos componentes de um sinal em amplitude e freqüência é que levará a correta identificação dos agentes causadores do fenômeno. Tipicamente, a 
análise do conteúdo de freqüências é realizada através de uma função matemática desenvolvida pelo físico e matemático francês Jean Baptiste Fourier (1768-1830). A Transformada de Fourier aplicada a um sinal $x(t)$ que se desenvolve no tempo faz sua transposição para o domínio da freqüência $X(\omega)$, conforme equação (1).

$X(\omega)=\int_{-\infty}^{+\infty} x(t) e^{-i \omega} d t$ equação (1)

Existem diversas formas de quantificar o valor da vibração, e aí se destacam técnicas de medição que levam em consideração as amplitudes das oscilações: zero-a-pico e pico-a-pico; os níveis de vibração em função do tempo: valor médio, e o nível de energia de vibração: valor quadrático médio (valor eficaz ou RMS) (figura 1).
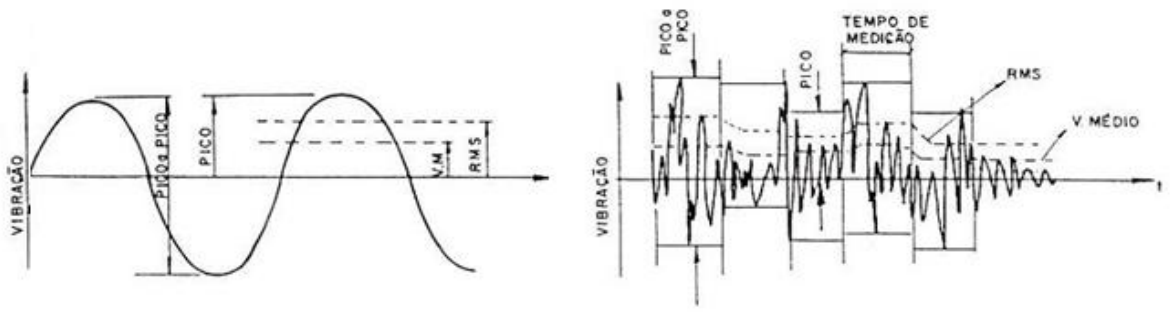

Figura 1 - Representação gráfica das formas de quantificação de vibração (ALMEIDA, 2003).

Para medir o nível vibratório em equipamentos de uma maneira mais básica, existe a medida do Valor Global de Vibração (overall), que consiste em expor através de um único número a quantificação das excitações em todas as faixas de freqüência (banda larga). A determinação desse parâmetro emprega a medição e compilação da intensidade total de vibração presente nos espectros coletados. O Valor Global poderá ser obtido para quaisquer grandezas que se desejem avaliar (deslocamento, velocidade ou aceleração). De maneira prática, pode se afirmar que consiste em realizar o somatório das influências de cada freqüência na energia total de vibração atuando sobre o equipamento (ALMEIDA, 2003).

\subsection{ANÁLISE DA RESPOSTA DO SISTEMA E CONTROLE DE VIBRAÇÃO}

O conhecimento das características das repostas em vibração associadas a defeitos comuns possibilita a identificação prévia dos mesmos nas mais diferentes máquinas, sem, no entanto, se fazer necessária uma desmontagem investigativa.

Há numerosas fontes de vibração em um ambiente industrial que tornam necessárias manutenções freqüentes e dispendiosas. O controle da vibração é facilitado quando o agente motivador é identificado pela análise da resposta do sistema, e muitas vezes, as altas amplitudes de 
vibração podem ser eliminadas por uma atuação prática simples, subsidiada por uma análise teórica bem feita (AMORIM, 2006). Diversos métodos são utilizados no controle das fontes de vibrações, são eles: Controle das freqüências naturais do sistema, inserção de mecanismos de amortecimento tais como: neutralizadores e absorvedores de vibrações; controle de folgas e eliminação de roçamentos.

\subsection{DIAGNÓSTICO DE DEFEITOS}

O diagnóstico de problemas em máquinas rotativas consiste em um processo de identificação das causas da origem da vibração mediante a análise das mesmas, fazendo-se assim necessário conhecer as características dos equipamentos e as principais peculiares associadas a potenciais falhas.

\subsubsection{DESBALANCEAMENTO, DESALINHAMENTO E ROÇAMENTO}

Eisenmann (1997) afirma que desbalanceamento é uma das fontes mais comum de vibração em máquinas e equipamentos, enquanto Inman (2004) cita que vibrações causadas por desbalanceamento normalmente dominam o espectro e ocorrem na freqüência de rotação ( 1 x RPM). O desbalanceamento acontece devido a uma alteração no equilíbrio das forças radiais que atuam sobre o eixo da máquina. A causa mais comum é o acúmulo de material sobre volantes de inércia, hélices de ventiladores, hélices de ventoinhas de motores, etc., mas pode ser causado também por perda de massa como a quebra de uma hélice, por exemplo. Se um componente específico (como ventilador, motor, rotor, por exemplo), é afetado individualmente por desbalanceamento, esse componente vibrará mais que os outros, mas se a fonte for um acoplamento, ocorre de todo conjunto da máquina vibrar. A figura 2 apresenta o espectro de uma bomba horizontal da Unidade 32 da RLAM (Unidade de Destilação Atmosférica e Vácuo), com a característica de desbalanceamento. 


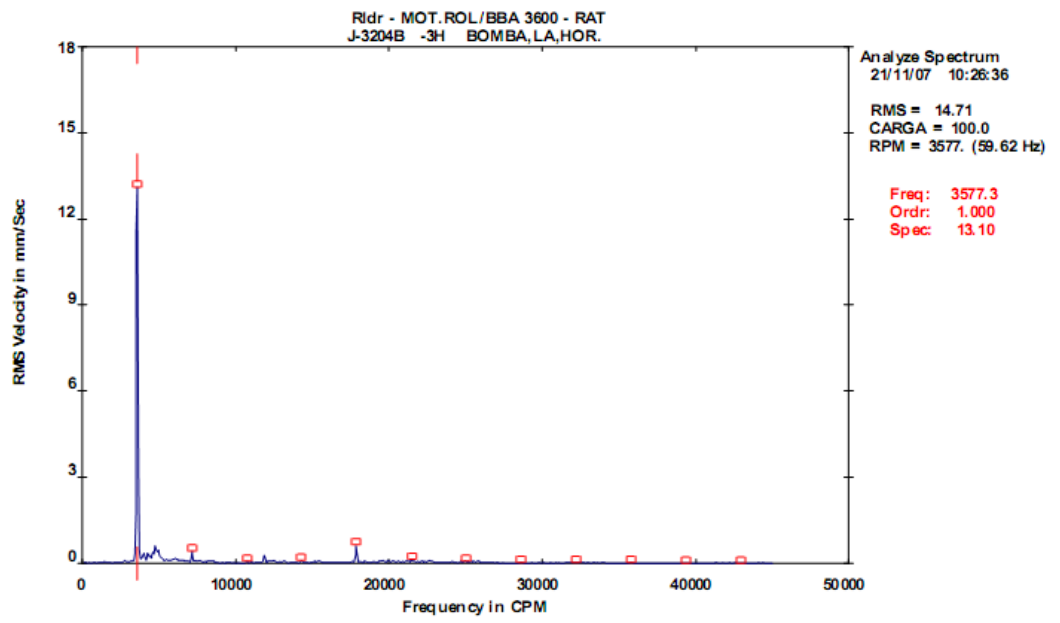

Figura 2 - Espectro de desbalanceamento (RLAM, 2007).

O desalinhamento (figura 3) é um problema tão comum como o desbalanceamento. Em uma montagem mecânica existem vários eixos, mancais e acoplamentos com características dinâmicas diferentes. Quando o conjunto gira as forças dinâmicas interagem entre si, excitando vibrações no sistema. Mesmo com as máquinas bem alinhadas inicialmente, à frio, vários fatores podem afetar esse estado, tais como a dilatação térmica dos metais (quando da máquina em funcionamento), os assentamentos de fundação e a deterioração de ancoragens (MELO, 2008).

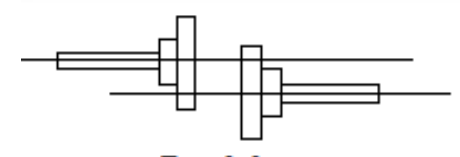

Paralelo

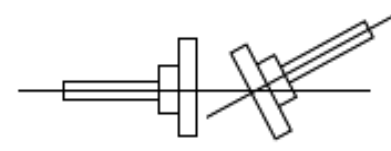

Angular

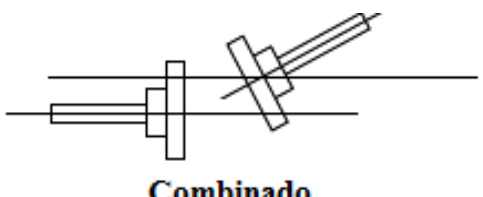

Combinado

Figura 3 - Tipos de desalinhamento (ANDRADE, 2004).

As características de vibração ocasionadas por desalinhamento dependem do tipo de desalinho e da extensão ou grau de desalinhamento. As características gerais são:

- Aparecimento de vibrações nas duas direções, na radial e na axial;

- O desalinhamento ocorre em uma certa direção, logo as forças radiais não serão uniformemente distribuídas e a vibração é direcional;

- Normalmente, a freqüência de vibração é a de rotação do eixo (1 x RPM); contudo, quando o desalinhamento é severo, a freqüência é de segunda ordem ( $2 \times$ RPM) e muitas vezes também de terceira ordem ( $3 \times$ RPM). $O$ desalinhamento angular geralmente causa vibração em 1 x RPM; o paralelo causa vibração predominante em 2 $x$ RPM. 
A figura 4 mostra desalinhamento típico em uma bomba vertical da Unidade 39 da RLAM (Unidade de Craqueamento Catalítico de Resíduo), com altas amplitudes nas freqüências de 1, 2 e 3 x RPM.

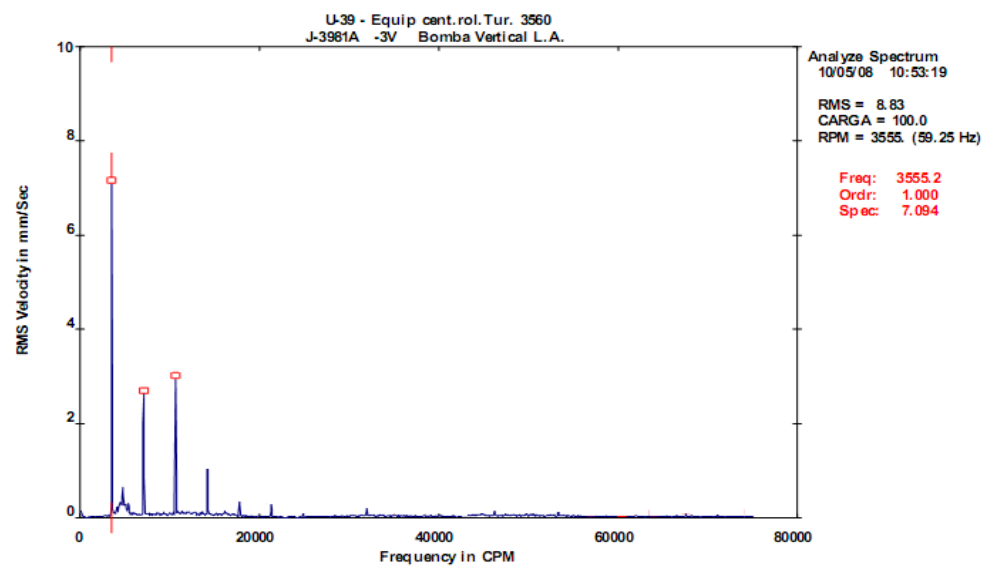

Figura 4 - Espectro de desalinhamento (RLAM, 2008).

O roçamento entre partes estacionárias e rotativas de uma máquina pode causar aumento dos níveis de vibração nas freqüências de $1 x$ e $2 x$ RPM. Se o atrito for contínuo poderão aparecer vibrações numa faixa larga em altas freqüências. Quando o roçamento for parcial, aparecem no espectro picos correspondentes às freqüências naturais do sistema.

A figura 7 apresenta um espectro característico de roçamento, encontrado em uma bomba vertical da Unidade 50 (bomba de incêndio) da RLAM.

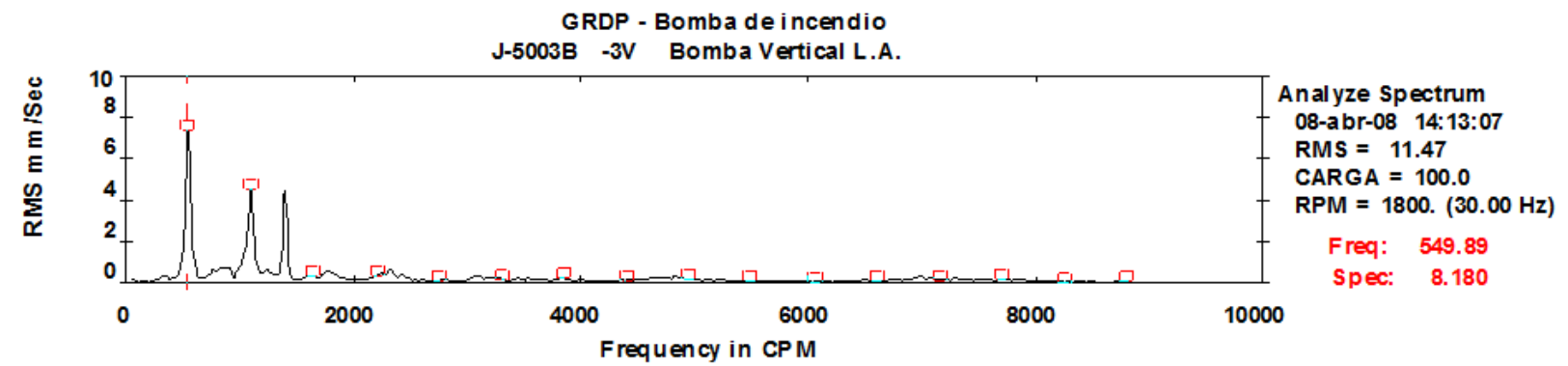

Figura 7 - Espectro característico de roçamento (RLAM, 2008).

Esse tipo de vibração é muito comum em selos de máquinas rotativas ou quando há eixos empenados, partes quebradas ou danificadas que levam ao atrito entre metal, situação que pode ocorrer por conta de babbit's danificados nos mancais. O roçamento produz espectros semelhantes 
aos das folgas mecânicas, e gera uma série de freqüências excitando uma ou mais ressonâncias (ANDRADE, 2004).

\subsubsection{FALHA EM MANCAIS DE ROLAMENTO}

Os rolamentos geram quatro freqüências características relacionadas a defeitos. Eles são relativos a falhas na pista externa, na pista interna, nas gaiolas e corpos rolantes. Essas freqüências são várias vezes a velocidade de rotação do eixo, porém não são necessariamente múltiplos inteiros dessa rotação (LAMIN, et al, 2006).

Mancais de rolamento com defeito sobre as pistas, esferas ou rolos, usualmente causam vibrações em altas freqüências. Isso se explica devido à natureza das forças dinâmicas que excitam o rolamento defeituoso gerando vibrações. Por exemplo, uma falha na esfera passa pelas pistas interna e externa em uma sucessão de impactos com o dobro da freqüência de rotação da esfera. A freqüência fundamental da vibração será bem mais alta do que a do eixo. Além disso, forças dinâmicas do tipo impulso geram vibrações de freqüência muito alta, na faixa de ressonância estrutural das pistas do rolamento. A amplitude da vibração dependerá da extensão da falha no rolamento. A figura 5 apresenta o espectro de vibração de uma bomba vertical da Unidade 18 da RLAM (Unidade de processamento de parafina e lubrificantes), com falha no mancal de rolamento.

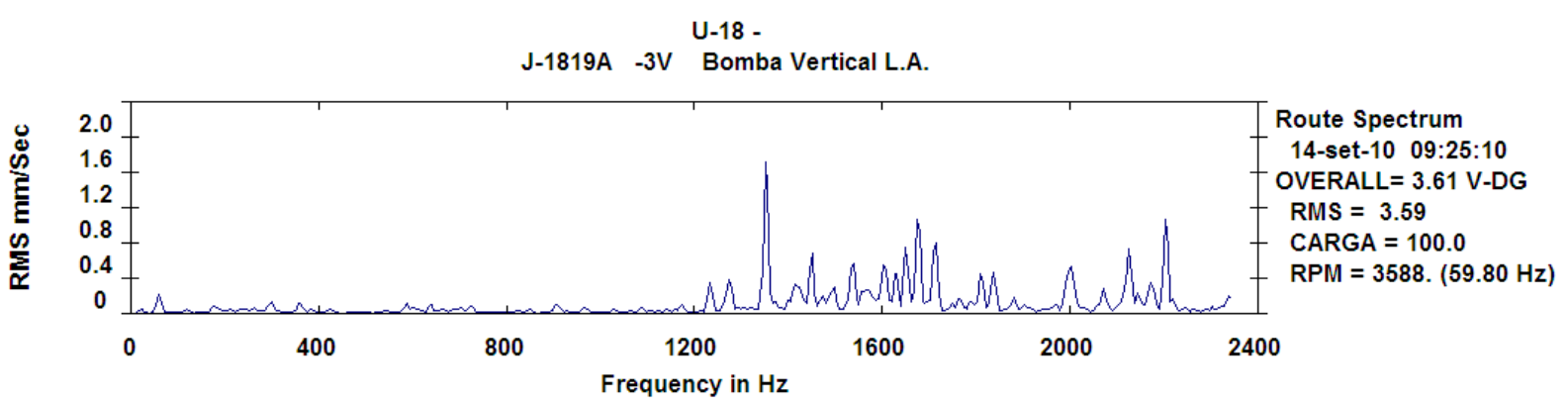

Figura 5 - Espectro de falha de rolamento (RLAM, 2010).

\section{BANCADA DE TESTES RLAM - CONJUNTO ROTOR-MANCAIS}

A Manutenção Industrial da RLAM dispõe de um setor denominado Preditiva, que se dedica ao acompanhamento contínuo dos parâmetros de funcionamento dos equipamentos dinâmicos que compõe a planta da Refinaria. A Manutenção Preditiva da RLAM faz uso das técnicas de análise de óleo, medição de temperatura e monitoramento dos níveis de vibração como ferramentas de identificação e acompanhamento de defeitos em diversos equipamentos.

A análise de vibração desponta como uma técnica de fundamental importância ao passo que disponibiliza os resultados das investigações de forma rápida e criteriosa, possibilitando tomadas de decisões de maneira consciente. Com o objetivo de difundir os conhecimentos relativos às técnicas de monitoramento de equipamentos rotativos, a RLAM 
possui uma bancada de testes que simula um conjunto rotor-mancal. Essa bancada é composta por uma base metálica, motor e acoplamento, eixo e disco de inércia, mancais de deslizamento e suportes para sensores (figura 8).

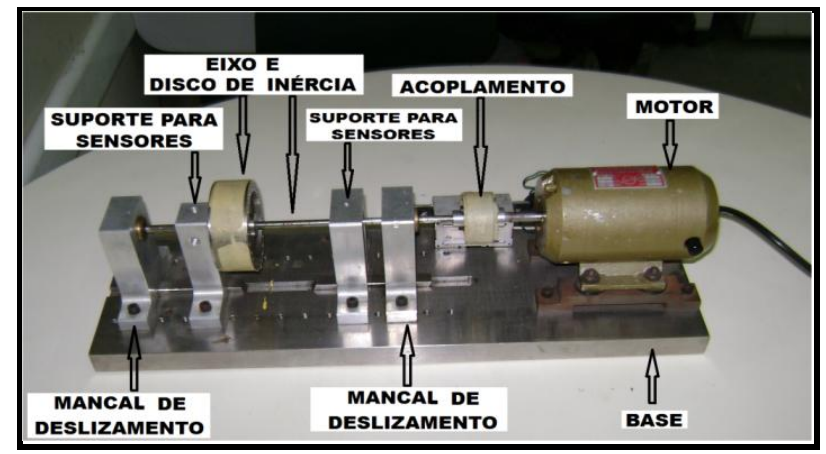

Figura 8 Bancada de teste da RLAM (RLAM, 2010).

\section{INSTRUMENTAÇÃO E ANÁLISE EXPERIMENTAL DA BANCADA DA RLAM}

O conhecimento a respeito da instrumentação a ser utilizada em coletas de dados é fundamental para se fazer uso das ferramentas corretas exigidas nas medições. Na especificação dos instrumentos e dos processos de medição usados na análise de vibração, é fundamental saber quais as informações requeridas, onde e como obtê-las, como condicioná-las convenientemente e também ter conhecimento sobre a melhor forma de apresentar os resultados e interpretá-los. Para uma aquisição que realmente ilustre a situação do equipamento estudado é necessário utilizar sensores apropriados, resolução adequada dos espectros e escolher pontos de coleta realmente representativos do comportamento da máquina.

\subsection{SENSORES UTILIZADOS NA BANCADA}

Na bancada da RLAM os transdutores (dispositivos que recebem um sinal e o retransmite, através de transformações de energia, fazendo uso, para isso, de elementos sensores) utilizam o principio do contato, onde é medido o movimento absoluto da máquina. Esses são os mesmos que os técnicos da Preditiva aplicam no cotidiano das medições e se caracterizam pela facilidade de transporte e montagem. No caso específico da RLAM, os transdutores são sensores de aceleração (acelerômetros)(ASH210-A) constituídos basicamente por uma massa sísmica e um cristal piezelétrico (figura 9), utilizados na condição de nível global dos sinais coletados, com sensibilidade de $100 \mathrm{mV} / \mathrm{g} \pm$ $5 \%$, banda passante de $0,5 \mathrm{~Hz}-15 \mathrm{kHz}$ e base magnética. 


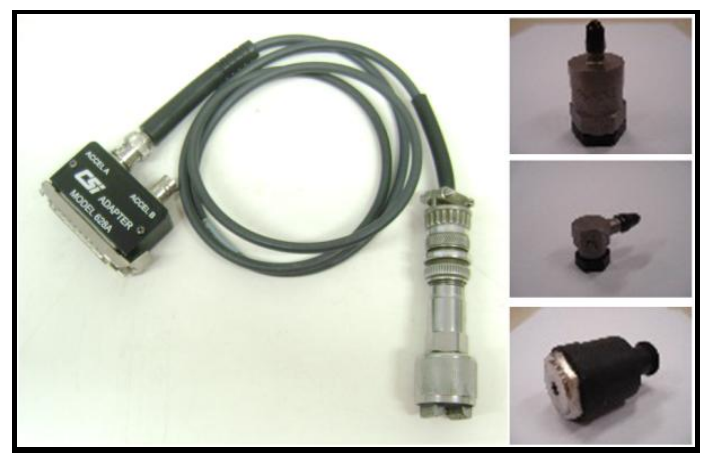

Figura 9 - Acelerômetros com cristal piezelétrico (RLAM, 2010; LAVIB, 2010).

\subsection{ANALISADOR PORTÁTIL}

Os analisadores portáteis, freqüentemente chamados de coletores de dados, são aparelhos desenvolvidos objetivando acompanhar e verificar o estado de funcionamento de equipamentos dinâmicos. São projetados para terem operação simplificada, incorporando funções pré-programadas de armazenamento de rotas (que são caminhos, seqüências de medição) e coleta rápida de dados.

O coletor de sinais utilizado na bancada é um analisador portátil CSI 2130, que apresenta processamento contínuo, display colorido, bateria com autonomia de oito horas e cabo de comunicação com entrada USB (EMERSONPROCESS, 2010) (figura 10).

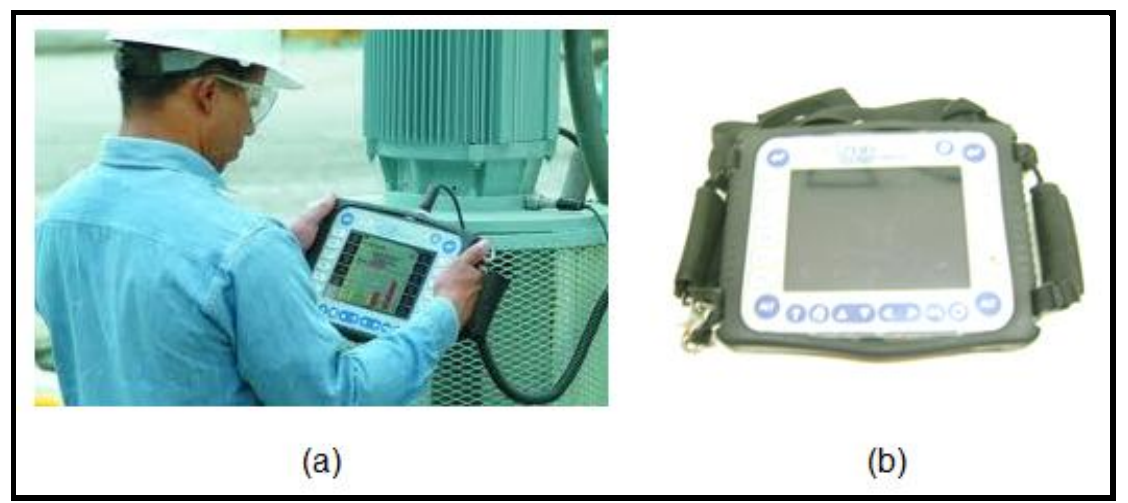

Figura 10 - Analisador portátil CSI 2130 ( (a) DRIVES\&CONTROLS, 2010; (b) RLAM, 2010).

\subsection{PONTOS DE AQUISIÇÃO DE DADOS}

Tendo em vista a condição que se deseja investigar, é preciso buscar um ponto externo acessível durante o funcionamento do equipamento, que seja portador das informações desejadas. A 
trajetória da vibração desde a fonte até o ponto de medida deve ser a mais sólida e curta possível, garantido máxima fidelidade na transmissão. Por esse motivo os pontos de medição devem ser sempre nos locais mais próximos da sustentação do equipamento. No caso dos equipamentos rotativos isso se dá nos mancais (DIAS, 2009).

$\mathrm{Na}$ bancada são executadas medições nas posições vertical, horizontal e axial de cada mancal, e é medida a vibração nessas direções também no motor (figura 11). O sinal foi aquisitado tanto no domínio do tempo com 1024 linhas, como no domínio da freqüência 1598 linhas. As medições foram realizadas para diversos pontos e obtidas para uma faixa de freqüência de 0 a $5000 \mathrm{~Hz}$ coletadas pelo analisador portátil.

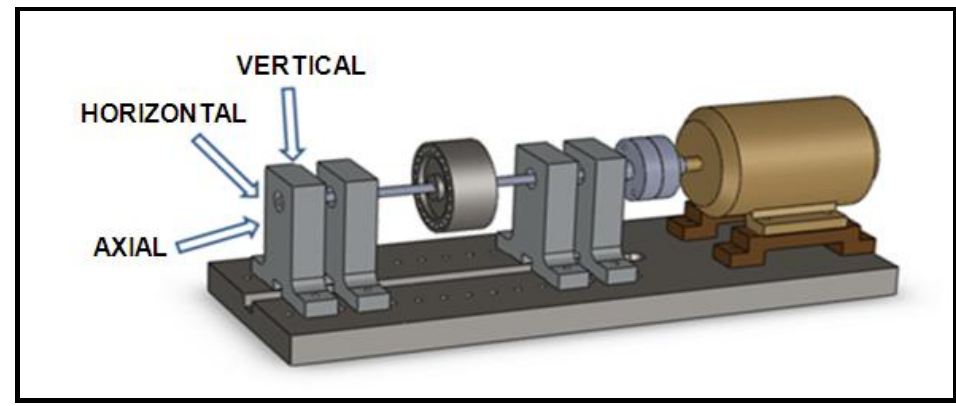

Figura 11- Pontos de aquisição de dados na bancada (LMC, 2010).

\subsection{ESTUDO DAS FUNÇÕES DE RESPOSTAS NA BANCADA}

Em primeiro momento é apresentada a resposta encontrada quando não foi incorporada nenhuma anomalia externa à bancada, ou seja, um estado tomado como padrão de referência. Em seguida, são mostrados os sinais de resposta quando são introduzidos desbalanceamentos de massa, desalinhamento e roçamento. Além disso, no decorrer da apresentação dos espectros de freqüência, são efetuados comentários sobre peculiaridades observadas.

\subsubsection{RESPOSTA DA BANCADA NA CONDIÇÃO REFERENCIAL}

A condição adotada como referencial se apresenta como aquela na qual nenhuma inclusão de irregularidade externa é aplicada sobre o aparato (figura 12). O motor da bancada é acionado e mantém velocidade de rotação estável. As respostas em vibração nesse estado trazem informações da situação dos componentes internos e permitem a comparação com ocasiões onde são introduzidos elementos que simulam falhas. 


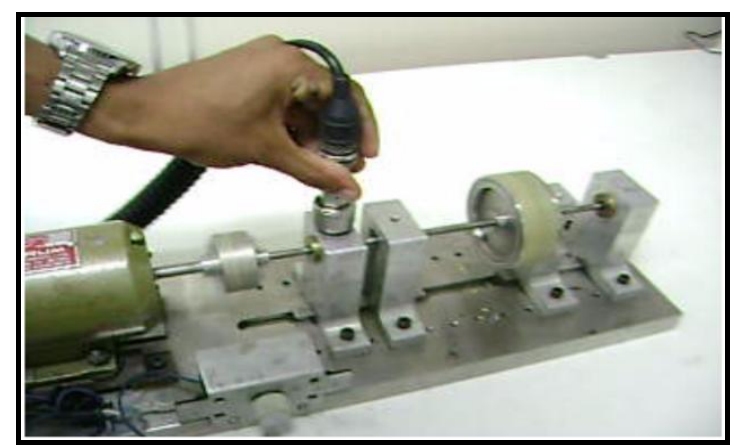

Figura 12 Medição da bancada na condição de referencia (RLAM, 2010).

Ao analisar o nível global de energia relacionada à vibração nessa condição, perceber-se que é baixo, confirmando a ausência de forças excitantes que estimulam vibrações em amplitudes elevadas (figura 13).

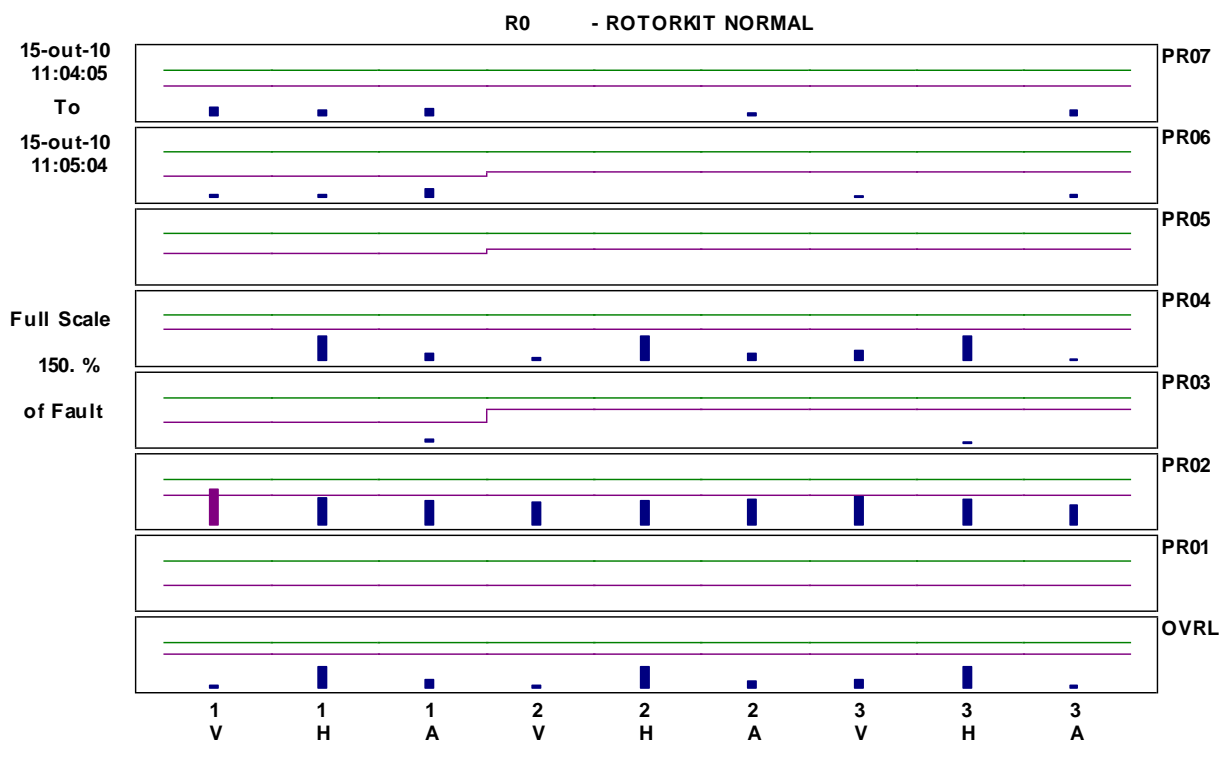

Figura 13 Nível global de energia na condição referencial (RLAM, 2010).

O gráfico exposto acima é uma representação dos níveis de energia relacionados aos modos de vibrar do equipamento. Na parte inferior da figura aparece a representação dos pontos de medida adotados para o estudo da bancada $(1 \mathrm{~V}, 1 \mathrm{H}, 1 \mathrm{~A}, 2 \mathrm{~V}, 2 \mathrm{H}$, etc.), sendo eles os postos verticais, horizontais e axiais do motor, do primeiro mancal e do segundo mancal, respectivamente. A figura também apresenta os níveis de vibração em bandas, ou seja, em faixas que cobrem desde as baixas até as altas freqüências. A faixa completa (banda larga) é dividida em sete bandas menores (sendo elas a PR01, PR02, PR03 até PR07), cada uma cobrindo uma determinada parcela do espectro na seqüência crescente de freqüências. Como somatório das influências de todas as faixas na energia de vibração total, é apresentado no retângulo inferior do gráfico o Valor Global de Vibração (overall). 
Uma observação ao analisar o gráfico da figura 13, é que o Valor Global de Vibração se apresenta com baixa intensidade, motivado por existirem apenas pequenas excitações. E é notável observar também, que os níveis de energia na direção horizontal $(1 \mathrm{H}, 2 \mathrm{H}, 3 \mathrm{H})$ são maiores que nas outras direções. Isso se explica pelo fato de haver maior liberdade para movimentações dos componentes físicos do equipamento nessa direção.

As figuras 14, 15 e 16 apresentam os espectros de freqüência relativos às medições nos pontos vertical, horizontal e axial do motor, respectivamente. Esses espectros estão correlacionados com o nível global de energia atuando sobre o equipamento (figura 13).

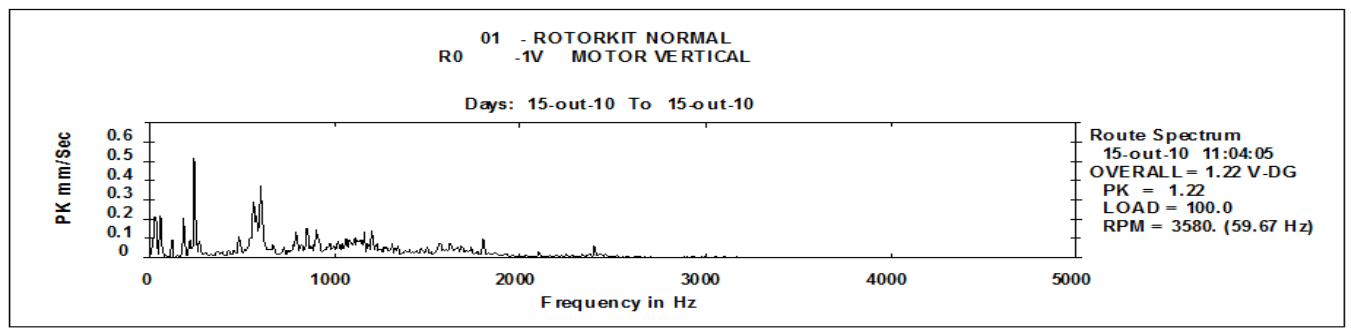

Figura 14 - Espectro de freqüencia relativo ao ponto vertical do motor (RLAM, 2010).

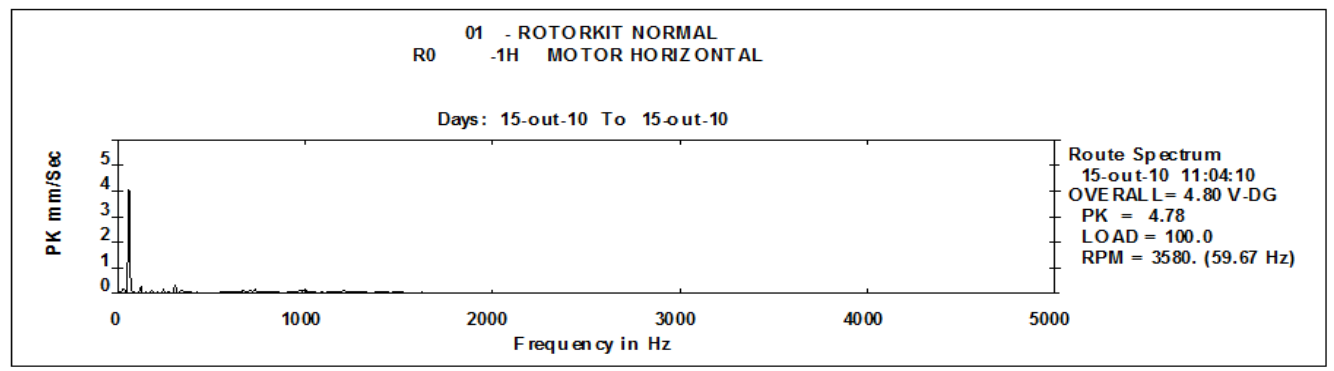

Figura 15 - Espectro de freqüencia relativo ao ponto horizontal do motor (RLAM, 2010).

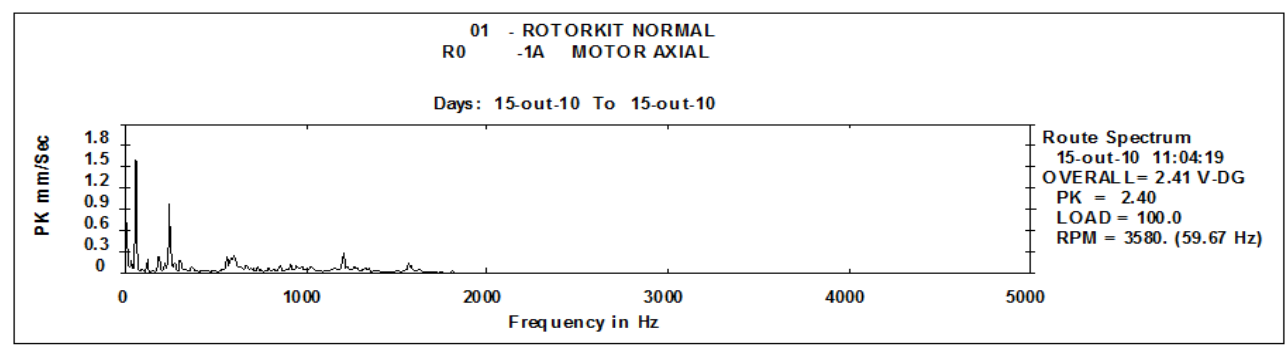

Figura 16 - Espectro de freqüência relativo ao ponto axial do motor (RLAM, 2010).

Analisando as informações contidas nesses gráficos observa-se o quanto a amplitude da vibração na direção horizontal é maior que nas demais (na horizontal atinge os $4 \mathrm{~mm} / \mathrm{seg}$. contra 
$0,5 \mathrm{~mm} / \mathrm{seg}$. na vertical e $1,5 \mathrm{~mm} / \mathrm{seg}$. na axial). Outro ponto interessante de ser ressaltado é proveniente da observação do espectro do ponto vertical do motor (figura 14). O motor apresenta mancais de rolamento e o que se percebe é que os mesmos começam a apresentar indicativo de falha, evidenciadas pela aparição de amplitudes maiores em altas freqüências (entorno de $1000 \mathrm{~Hz}$ ), porém as amplitudes ainda são baixas, indicando que o problema está em fase inicial.

Após a análise do estado tomado como padrão, segue as observações resultantes da simulação de defeitos típicos de equipamentos rotativos, salientando as características mais acentuadas.

\subsubsection{RESPOSTA DA BANCADA SUJEITA A DESBALANÇO DE MASSA}

A simulação do desbalanço é produzida pela introdução de massa descentralizada no rotor do conjunto. A quantidade de massa e o raio de excentricidade têm influência direta no Valor Global de Vibração. Para o estudo dessa condição são introduzidos parafusos na periferia do disco de inércia do rotor. Com o objetivo de observar os efeitos do aumento de massa no desbalanço, duas situações são investigadas, uma quando se introduz massa de $0,5 \mathrm{~g}$ e outra onde uma massa de $3,5 \mathrm{~g}$ é inserida (figura 17).

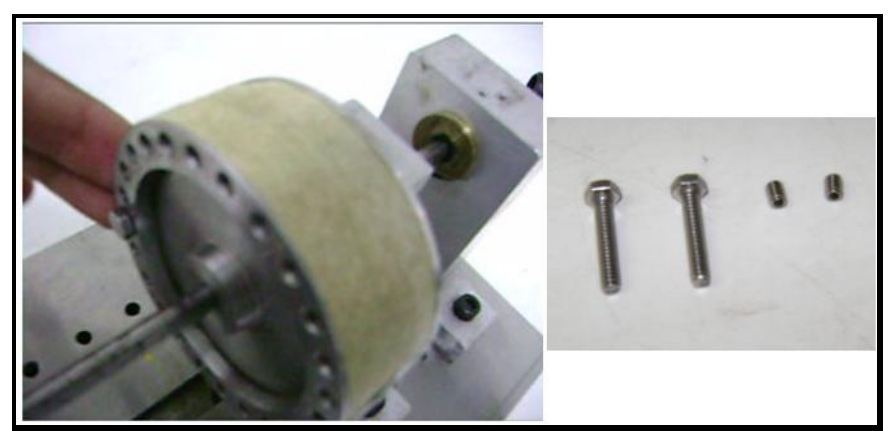

Figura 17 - Simulação de desbalanceamento (RLAM, 2010).

A figura 17 apresenta o primeiro caso, quando é inserido o parafuso de 0,5g. Fica perceptível a diferença no nível de energia (figura 18) quando comparado com a condição de referência (figura 13). Existe um pequeno aumento de intensidade nas bandas de freqüências e, logo, no Valor Global de Vibração. 


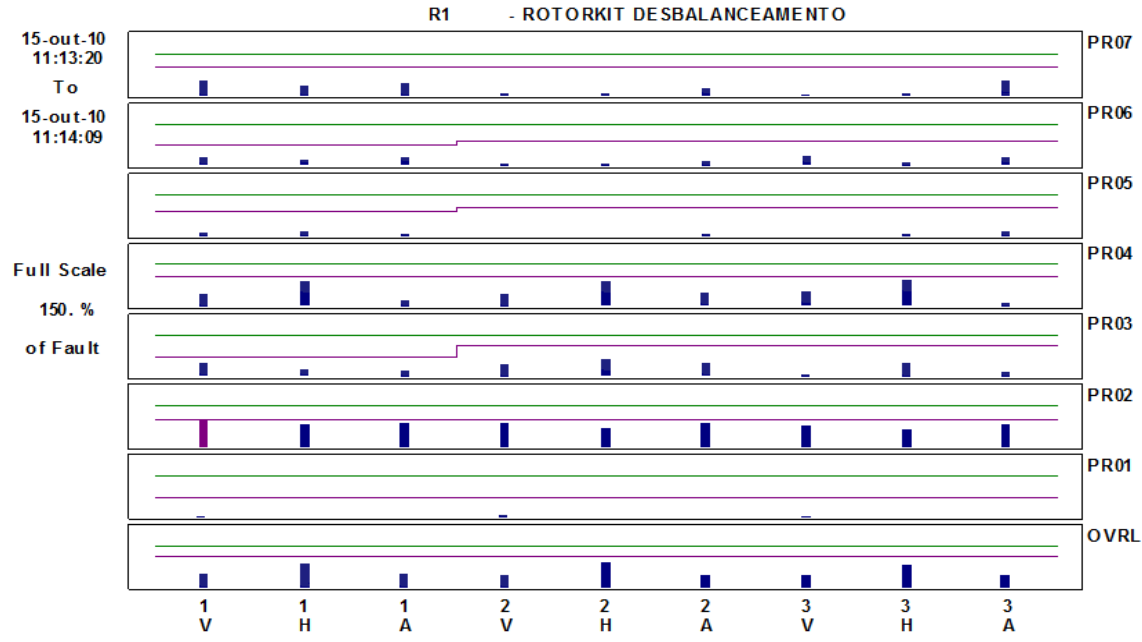

Figura 18 - Nível global de energia na condição de desbalanceamento com 0,5g (RLAM, 2010).

As vibrações causadas por desbalanceamento ocorrem na freqüência de rotação ( 1 x RPM) e geralmente as amplitudes maiores se dão nas direções radiais, e é o que pode ser comprovado com a análise dos espectros a seguir. A rotação de trabalho adotado nas simulações é de aproximadamente $60 \mathrm{~Hz}$ (3600 RPM) (figura 19), e é nessa rotação que fica estabelecido os maiores deslocamentos.

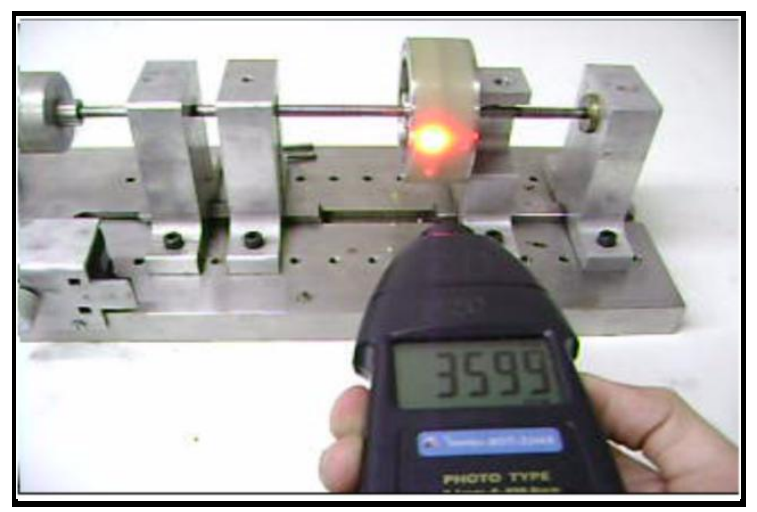

Figura 19 - Medida da rotação de trabalho adotada (RLAM, 2010).

As figuras 20, 21 e 22 trazem as maiores intensidades de vibração, sendo elas relacionadas (como poderia ser deduzido ao examinar o Nível Global de Energia da figura 4.11) aos pontos horizontais do motor, do primeiro e do segundo mancal respectivamente. 


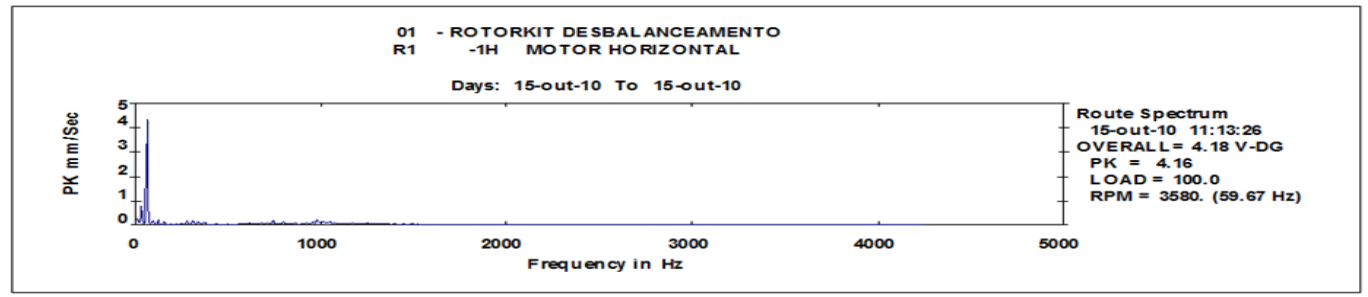

Figura 20 - Espectro de desbalanço de 0,5g medido no ponto horizontal do motor (RLAM, 2010).

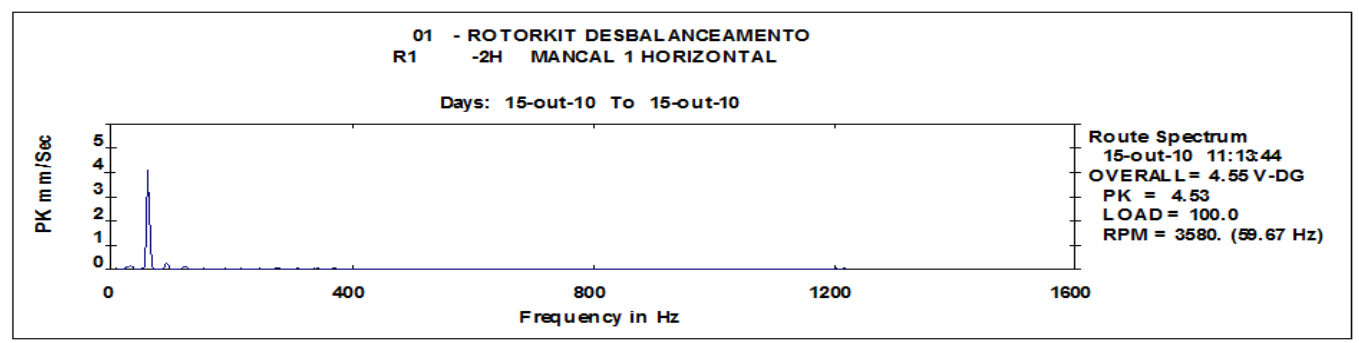

Figura 21 - Espectro de desbalanço de 0,5g medido no ponto horizontal do 10 mancal (RLAM, 2010).

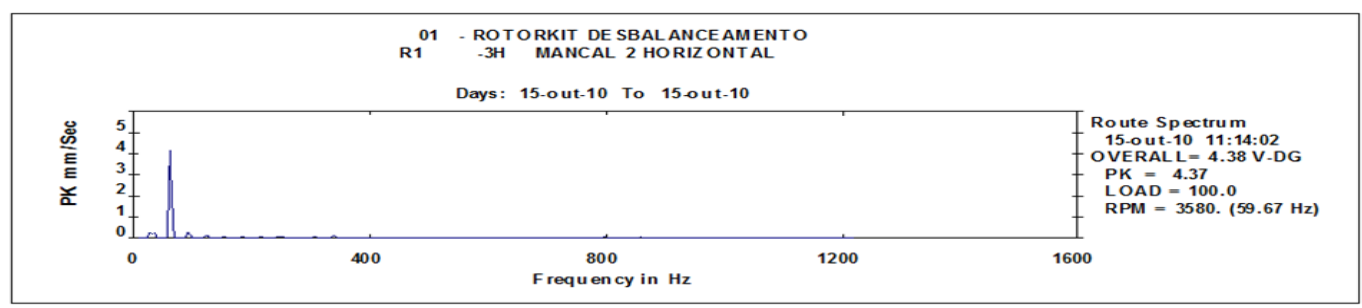

Figura 22 - Espectro do desbalanço de 0,5g medido no ponto horizontal do 20 mancal (RLAM, 2010).

A figura 23 trás o estudo do segundo caso, quando é inserida a massa descentralizada de $3,5 \mathrm{~g}$. É nítida a diferença no nível de energia quando comparado com a condição referencial (figura 13) e com a condição de desbalanço apresentado na figura 18 (com massa excêntrica de 0,5g). Existe um grande aumento de intensidade em todas as bandas freqüências e também no Valor Global de Vibração. É interessante ressaltar que nessa condição o nível de ruído é muito elevado, tornando-se um incômodo. 


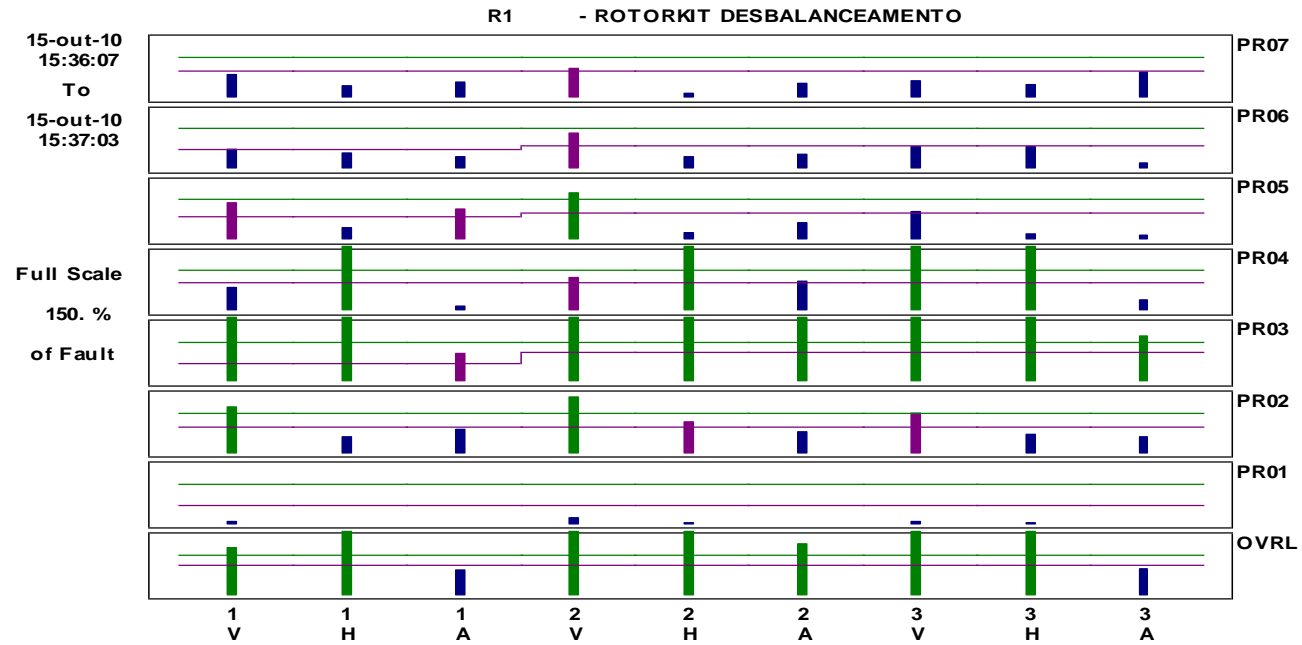

Figura 23 - Nível global de energia na condição de desbalanceamento com 3,5g (RLAM, 2010).

Enquanto no primeiro desbalanceamento estudado a máxima amplitude era em torno de 4 $\mathrm{mm} / \mathrm{seg}$. nessa segunda simulação as maiores amplitudes chegam a casa de $50 \mathrm{~mm} / \mathrm{seg}$. Os espectros dos pontos mais excitados nessa condição de desbalanceamento são expostos nas figuras 24 e 25 e é possível perceber que as maiores amplitudes se dão na mesma freqüência de rotação do eixo (em torno de $60 \mathrm{~Hz}$ ).

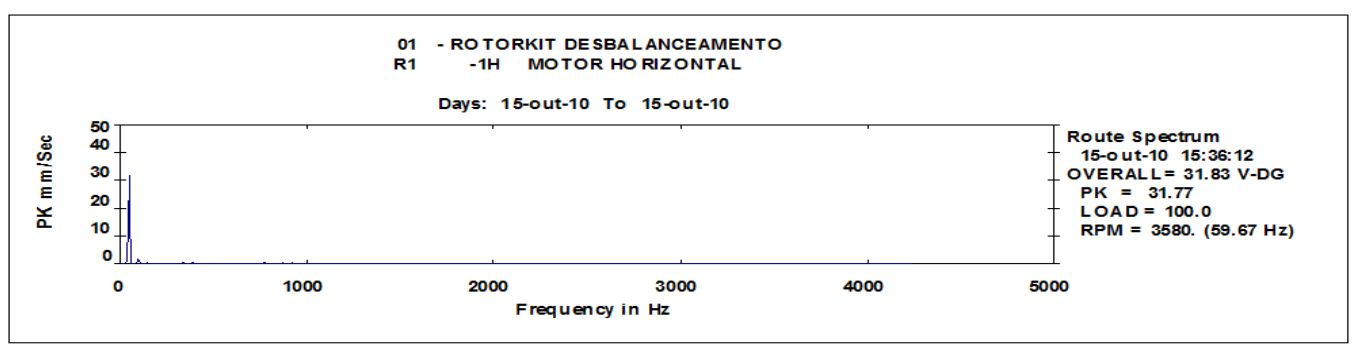

Figura 24 - Espectro do desbalanço de 3,5g medido no ponto horizontal do motor (RLAM, 2010).

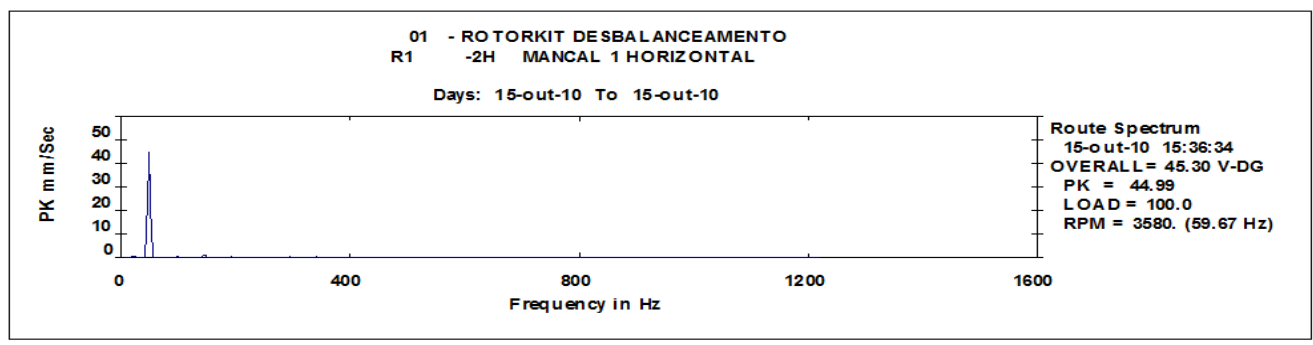

Figura 25 - Espectro do desbalanço de 3,5g medido no ponto horizontal do 19 mancal (RLAM, 2010). 


\subsubsection{RESPOSTA DA BANCADA SUJEITA A DESALINHAMENTO VERTICAL}

O desalinhamento simulado na bancada consiste em promover uma diferença no paralelismo dos mancais. Para isso, sob o mancal mais próximo ao acoplamento entre o motor e o eixo (1은 mancal), são introduzidas finas chapas de aço (calços) que o eleva (figura 27). Os resultados das medições efetuadas com um desalinhamento vertical de $1 \mathrm{~mm}$ são apresentadas a seguir.

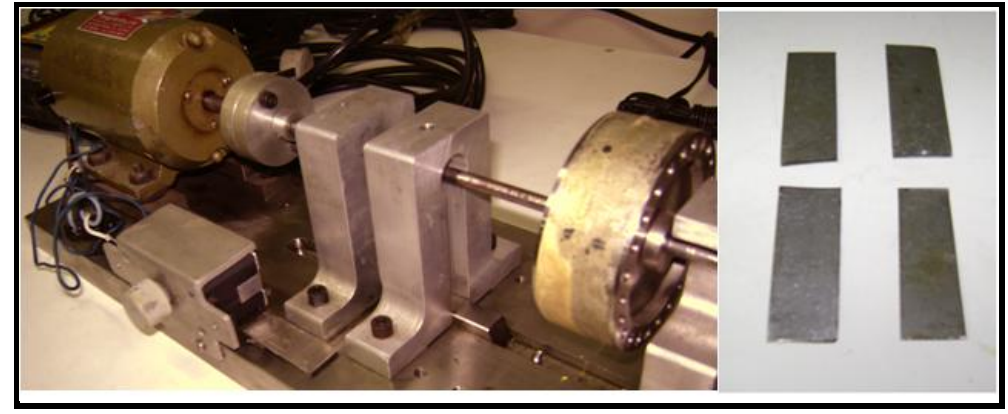

Figura 27 - Material para Simulação de desalinhamento (RLAM, 2010).

Primeiramente é interessante avaliar o nível global de excitação e compará-lo com a condição tomada como referência (figura 13). A figura 28 apresenta a situação com o desalinhamento e é possível observar que não há grande elevação nos índices de energia. Comparando os valores de overall chega-se a conclusão que são muito parecidos.

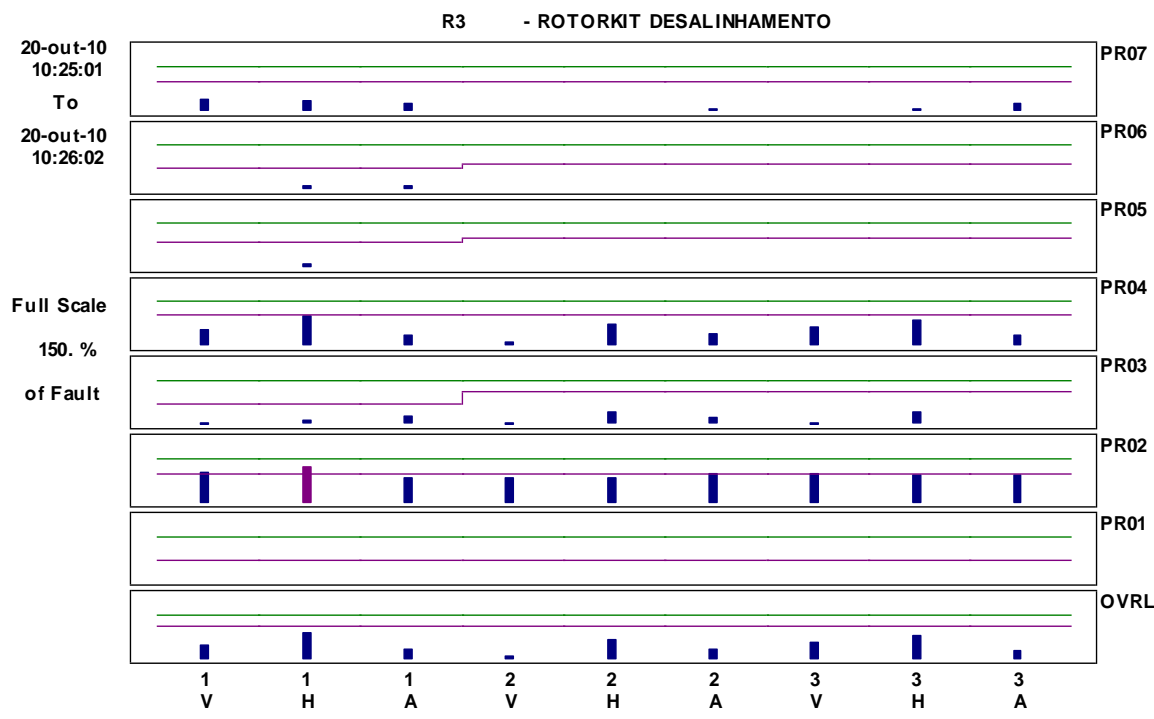

Figura 28 Nível global de energia na condição de desalinhamento (RLAM, 2010). 
Uma peculiaridade referente aos mancais de deslizamento é a existência de folgas internas que tendem a compensar pequenos desalinhamentos. Por esse motivo os níveis de energia não se alteram bruscamente, como observado nos casos de desbalanceamento.

Com a análise das amplitudes nos espectros de freqüência tem-se que elas também não sofreram mudanças bruscas. Porém, o estudo desses espectros permite caracterizar a típica situação de desalinhamento paralelo, onde as vibrações são predominantes em duas vezes a rotação do eixo (2 $x$ RPM, em torno de $120 \mathrm{~Hz}$ ). Também é perceptível que pequenos aumentos de amplitude se dão na direção radial e axial, o que pode ser constatado nas figuras 29 e 30, as quais comparam os espectros da condição de referência com os do desalinhamento, medidos no primeiro mancal nas direções vertical e axial.

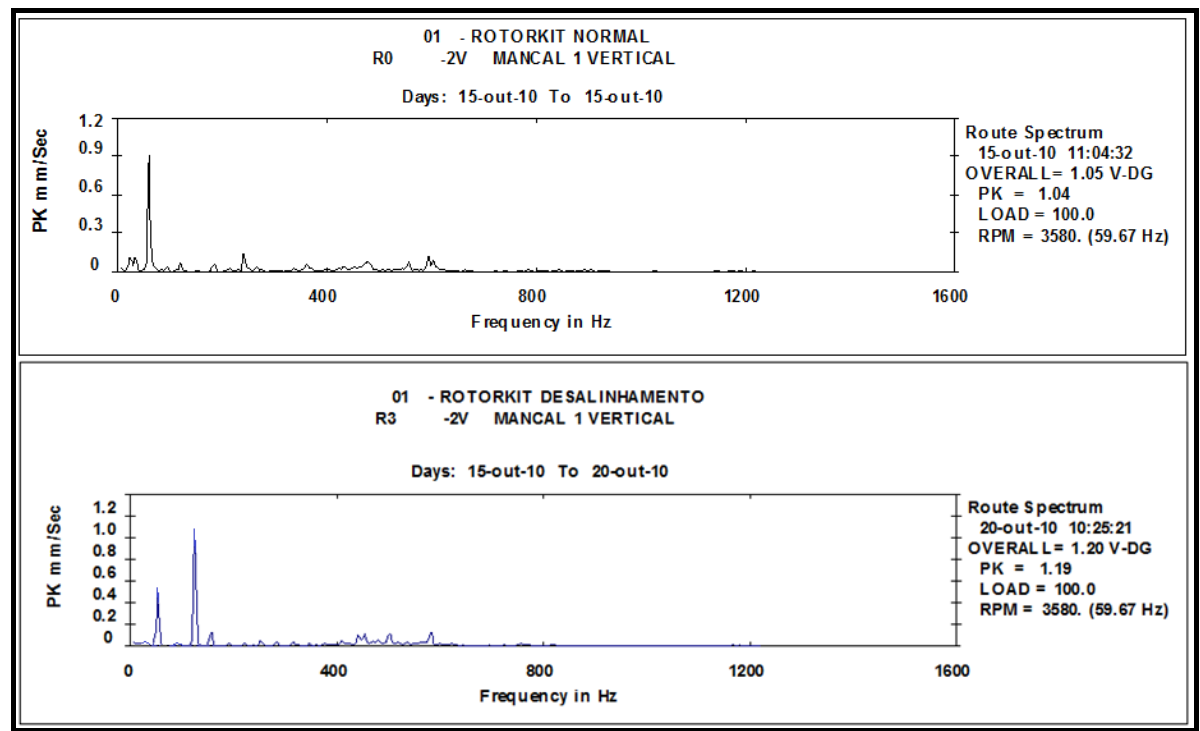

Figura 29 - Espectros do mancal 1 V na condição referencial e com desalinhamento (RLAM, 2010).

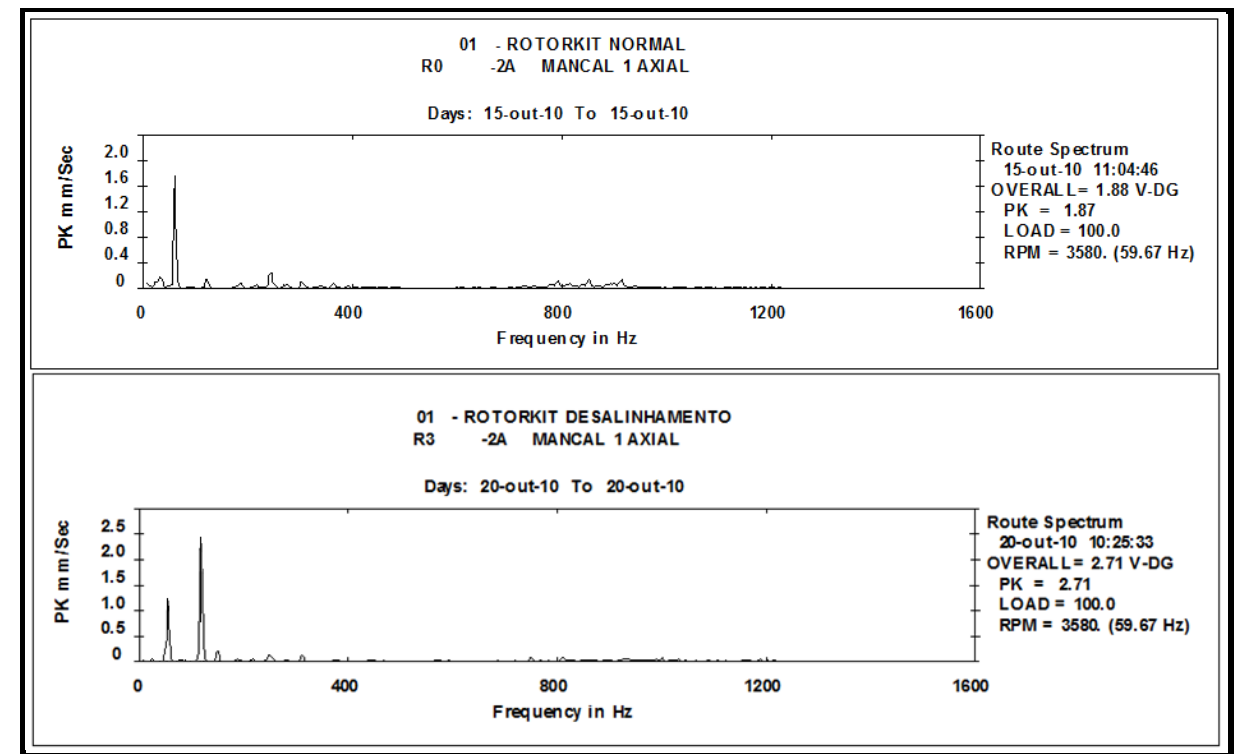

Figura 30 - Espectros do mancal 1 A na condição referencial e com desalinhamento (RLAM, 2010). 


\subsubsection{RESPOSTA DA BANCADA SUJEITA A ROÇAMENTO}

A simulação do roçamento é obtida pela introdução de atrito sobre os componentes dinâmicos da bancada. A fricção estabelecida consiste em fazer roçar a ponta de um parafuso contra o eixo girante, e a intensidade é controlada pelo nível de pressão estabelecido no aperto do parafuso (figura 31).

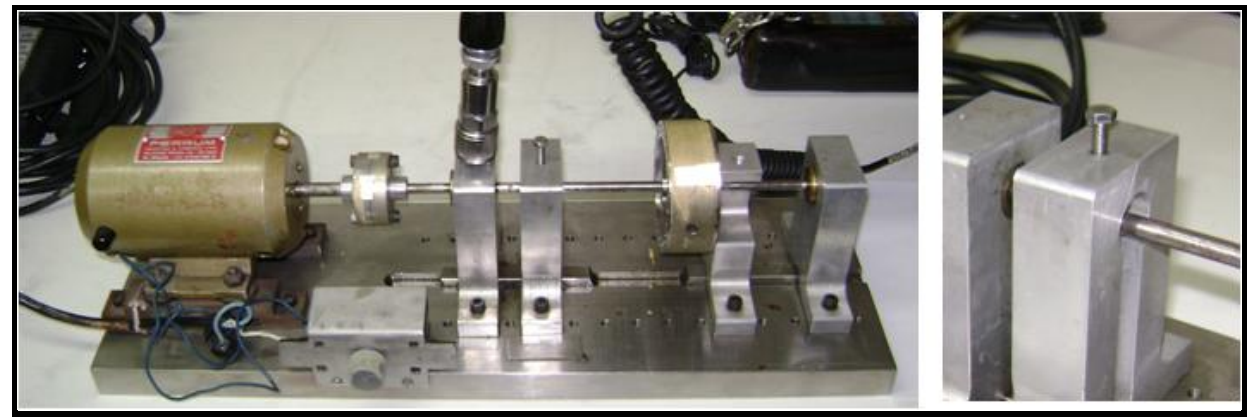

Figura 31 - Simulação de roçamento (RLAM, 2010).

O gráfico de energia resultante da imposição de uma pequena pressão do parafuso sobre o eixo é ilustrado na figura 32. Contudo, mesmo sendo baixa a quantidade de atrito, o roçamento tende a elevar as vibrações. É importante salientar que a quantidade de ruídos resultante dessa simulação é grande e incomoda, desfavorecendo testes de maior intensidade.

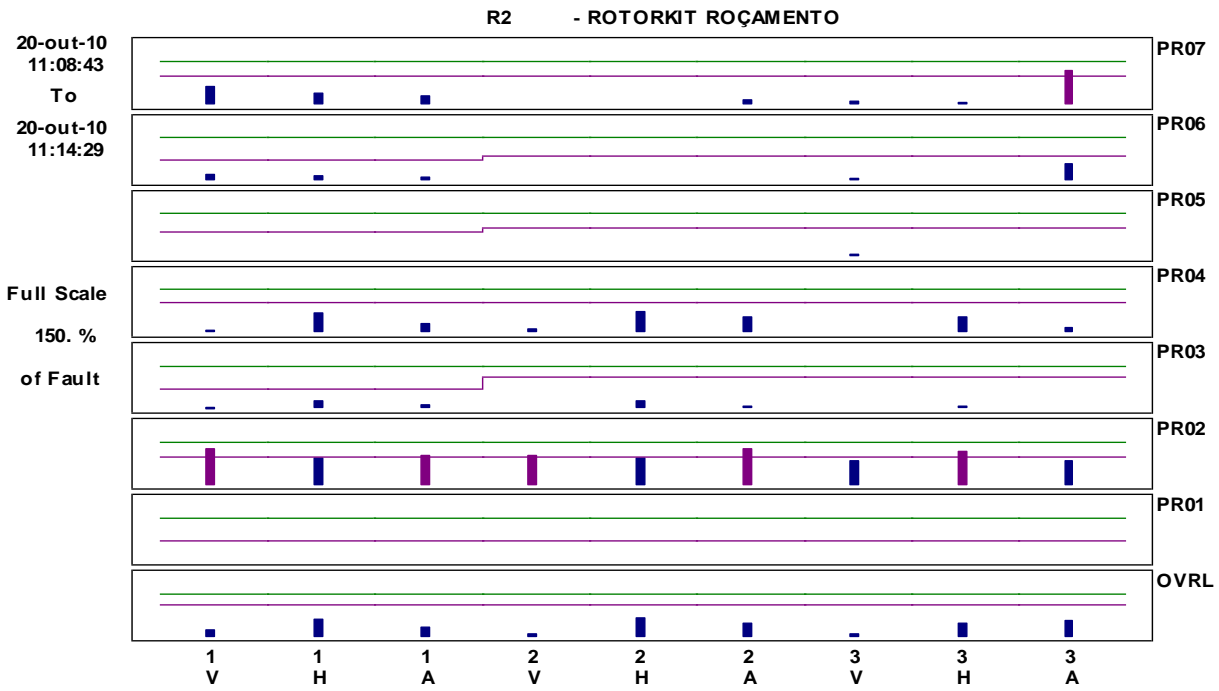

Figura 32 - Nível global de energia na condição de roçamento (RLAM, 2010). 
A comparação da figura acima, com a figura 13 (condição de referência) revela uma pequena elevação na energia vibracional. Porém, o estudo dos espectros é que revela a característica principal do roçamento. $O$ atrito contínuo aplicado promove a aparição de vibrações em uma faixa larga nas altas freqüências, resultantes da excitação de diversas ressonâncias na máquina. As figuras 33 e 34 trazem as respostas ao teste estabelecido, onde se percebe que as amplitudes são pequenas, devido ao baixo nível de atrito imposto, porém os picos de vibração estão presentes nas altas freqüências.

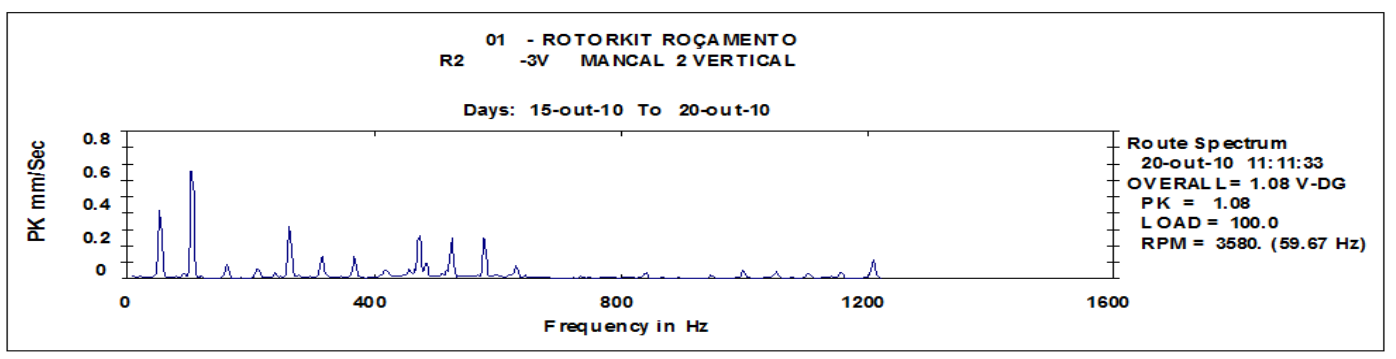

Figura 33 - Espectro do roçamento medido no ponto vertical do segundo mancal (RLAM, 2010).

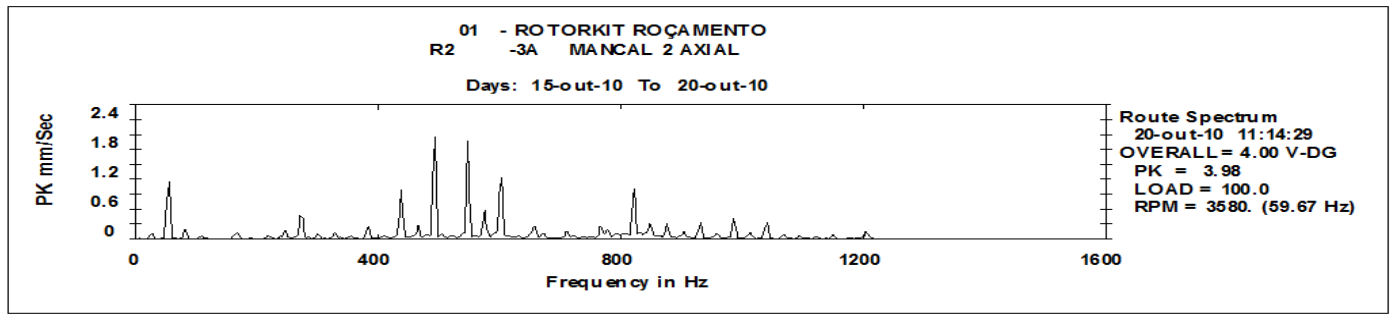

Figura 34 - Espectro do roçamento medido no ponto axial do segundo mancal (RLAM, 2010).

\section{CONCLUSÕES}

O estudo do comportamento dinâmico de equipamentos rotativos, realizado ao longo desse trabalho, possibilitou conhecer definições, conceitos básicos, características principais e parâmetros que regem a Ciência das Vibrações Mecânicas. A discussão a respeito dos principais problemas que acometem as máquinas rotativas tornou possível avaliar como se processa a identificação e o diagnóstico de falhas, baseando-se nas respostas em freqüência emitidas pelos maquinários em funcionamento. Conforme se observa no espectro da resposta em freqüência, nos pontos próximos ao motor ( Fig. 15 e 16), o nível de vibrações é bastante alto na direção horizontal $(4,0 \mathrm{~mm} / \mathrm{seg}$ ) quando comparado com a direção vertical $(0,5 \mathrm{~mm} / \mathrm{seg})$. Ou seja, quando comparado com o nível global de energia existem amplitudes maiores nesta direção.

$\mathrm{Na}$ análise da resposta ao desbalanceamento, as maiores amplitudes ocorrem em pontos próximos ao motor, considerando uma massa de 0,5 g. Enquanto que, por outro lado, para uma massa 
de 3,5 g, estas amplitudes ocorrem em pontos próximos aos mancais na direção horizontal. Nesta condição, observou-se que o nível de ruído é bastante elevado.

Com relação ao fenômeno de desalinhamento, foi sugerido inicialmente a inserção de pequenos calços, próximo ao motor e o 1 - mancal, para simular tal efeito. Inicialmente foi feito a análise do nível global e verificaram-se níveis de vibrações predominantes em freqüências múltiplas da freqüência de rotação do eixo, próximas a $120 \mathrm{~Hz}$. As maiores amplitudes de freqüências ocorreram em pontos próximos ao mancal 1.

$\mathrm{Na}$ análise do fenômeno do roçamento, foi inserido no cabeçote do mancal um parafuso cuja extremidade, roçava a superfície do eixo. O nível de atrito foi controlado pelo torque no parafuso. Observou-se que para pequeno nível de roçamento, grandes níveis de energia global foram verificados no sistema. Mesmo para baixo nível de atrito, o sistema foi excitado em larga faixa de freqüências considerada alta.

Os estudos de casos, onde foram simulados desbalanceamentos, desalinhamento e roçamento, comprovou as afirmações teóricas sobre os diagnósticos de defeitos, mostrando que determinadas falhas apresentam um padrão bem definido de vibração. Além disso, a análise dos níveis de energia e dos espectros de freqüências relacionados à simulação dessas falhas possibilitou uma maior familiarização com parâmetros fundamentais para a investigação continuada de equipamentos.

\section{REFERÊNCIAS}

1. ALMEIDA, M. Tadeu; GÓZ, R. D. Sales (2003). Análise de Vibrações I - Medida e Diagnósticos. Apostila do Curso de Análise de Vibrações da FUPAI, Itajubá - MG.

2. AMORIM, M. José (2006). Desenvolvimento de uma Bancada Didático-Experimental de Baixo Custo para Aplicação em Controle Ativo de Vibrações. Dissertação (Mestrado em Engenharia Mecânica) - Universidade Estadual de Campinas, Campinas - SP.

3. ANDRADE, A. F. Abreu de (2004). Introdução ao Monitoramento de Equipamentos por Análise de Vibrações. Apostila SENAI - CIMATEC, Salvador - BA.

4. BRYAN, D.; BRGLEZ, F. and KOIMINSKI, K. (1989). Combinational Profiles of Sequential Benchmark Circuits. In IEEE International Symposium on Circuits and Systems, volume 3, pages 1929 - 1934.

5. DIAS, A. dos Santos, RODRIGUES J. das Chagas e RAMALHO, G. L. Bezerra (2009). Detecção de Falhas em Máquinas Rotativas Através da Análise de Vibração. IV Congresso de Pesquisa e Inovação da Rede Norte e Nordeste de Educação e Tecnologia. Belém - PA.

6. EMERSONPROCESS. Folder Especificações Técnicas do CSI 2130. Disponível em: < http//www.EmersonProcess.com.br > Acessado em 20 de set. 2010. 
7. EISENMANN, Robert C. Sr. And Eisenmann, Robert C. Jr.(1997), Machinery Malfunction Diagnosis and Correction: vibration analysis and troubleshooting for the process industries, New Jersey, Prentice-Hall, Inc.

8. INMAN, J. Daniel (2004), Engineering Vibration, Pearson Prentice Hall, Third Edition, New Jersey.

9. KIROVSKI, D.; LEE, C.; HONG, I. and POTKONJAK, M. (1997). Dsp quant: Design, Validation, and Applications of dsp Hard Real-time Benchmark. In IEEE International Conference on Acoustics,Speech, and Signal Processing, volume 1, pages $679-682$.

10. LAMIM FILHO, P. ABREU, R. D. A. ; BRITO, J. N. (2007). Diagnóstico de Falhas em Rolamentos Utilizando as Técnicas de Decomposição em Wavelet e Deteç̧ão de Envelope. Anais do 8o Congresso Iberoamericano de Engenharia Mecânica, Cusco.

11. LMC (2010). Laboratório de Mecânica Computacional da UFBA. Departamento de Engenharaia Mecânica. Escola Politécnica. Salvador-BA.

12. LAVIB (2010). Laboratório de Vibrações. Departamento Acadêmico de Mecânica Universidade $\begin{array}{lllll}\text { Tecnológica } & \text { Federal Daraná. }\end{array}$ <http//www.ppgem.ct.utfpr.edu.br/lavib/index.html> Acessado em 08 de jul. de 2010.

13. MELO, M. Arco-Verde (2008), Identificação de Falhas em Sistemas Rotativos Empregando Técnicas não Lineares. Dissertação (Mestrado em Engenharia Mecânica) - Universidade Federal do Rio de Janeiro, Rio de Janeiro - RJ.

14. OlIVEIRA, A. Gonçalves de, (1999). Técnicas de Caracterização de Excitações em Máquinas Rotativas. Tese (Doutorado em Engenharia Mecânica) - Universidade Federal de Uberlândia, Uberlândia - MG.

15. RAO, S. Singiresu (2009). Vibrações Mecânicas, Pearson Prentice Hall, Quarta Edição, São Paulo.

16. RLAM. Arquivos Técnicos. Refinaria Landulpho Alves de Mataripe. Petróleo Brasileiro SA PETROBRAS. São Francisco do Conde, BA.

17. SILVA, Samuel da (2009). Vibrações Mecânicas. Notas de aula - 2o Versão. Universidade do Oeste do Paraná. Foz do Iguaçu - PR. 